\title{
Empowering the Electronics Industry: A Power Technology Roadmap
}

\author{
Conor A. Quinn and Dhaval B. Dalal
}

\begin{abstract}
The Power Sources Manufacturers Association (PSMA) currently publishes an updated Power Technology Roadmap (PTR) every two years. This paper describes the methodology used and the key findings captured in the tenth edition which was published in March 2017. Applications driving the roadmap needs are presented along with the direction of technology advancement in components, power supplies and converters. Emerging technologies which promise the potential of further advancement, but are not yet proven, are also discussed.
\end{abstract}

Index Terms-Emerging technologies, power technology, PSMA, PTR, roadmap.

\section{INTRODUCTION}

$\mathrm{T}$ HE Power Technology Roadmap (PTR) published by the Power Sources Manufacturers Association (PSMA) helps align the power electronics industry by tying together the needs and direction of a broad range of stakeholders.

The latest roadmap document published in 2017 exceeds 500 pages [1]. This paper merely provides a summary of how the roadmap is assembled and offers a flavor of the type of content that is included.

The purpose of the PSMA, a not-for-profit organization, is to enhance the stature and reputation of its members and their products; improve their knowledge of technological and other developments related to power sources; and educate the electronics industry, academia, and government and industry agencies as to the importance of, and relevant applications for, all types of power sources and conversion devices. The membership ranges from Original Equipment Manufacturers (OEMs) who use and specify power conversion equipment, through manufacturers of power supplies and converters, to component manufacturers of active and passive devices. The membership also includes individuals involved in power electronics consulting and institutions involved in academic and pre-commercial research and development in the area.

To support the purpose of improving knowledge of technological and other developments related to power sources, a PTR committee is sponsored with the purpose of regularly publishing a roadmap document to help guide and align the members and other stakeholders. The roadmap document is currently pub-

Manuscript received on 28 November, 2017. This work was part of the PSMA Power Technology Roadmap effort from 2015 to 2017.

C. A. Quinn is with Artesyn Embedded Technologies, Eden Prairie, MN 55344, USA (e-mail: conor.quinn@artesyn.com).

D. B. Dalal is with ON Semiconductor, Phoenix, AZ 85008, USA (e-mail: dhaval.dalal@onsemi.com).

Digital Object Identifier 10.24295/CPSSTPEA.2017.00028

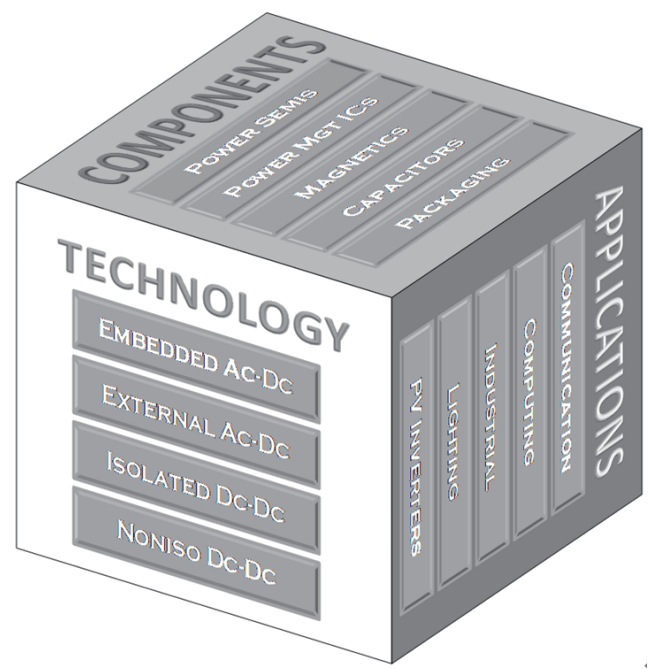

Fig. 1. Power technology roadmap cube.

lished every two years and this paper reviews the methodology and contents of the tenth edition published in March 2017.

While some enhancements in gathering and presenting data are being considered for the eleventh edition, the committee envisions that the basic format of the tenth edition will carry into the next edition.

\section{Methodology}

In March 2015, in conjunction with the APEC conference, the PSMA PTR committee held a kick-off meeting to review the scope of the report. There was also a lessons-learned analysis of the just released PTR 2015 report to facilitate learnings and improvements. Like the previous roadmap, the report's structure remained a three-dimension overview of:

- Power Supply \& Converter products and technology (ac-dc front-end power supplies, external ac-dc supplies, isolated and non-isolated dc-de converters)

- Components Technologies (power semiconductors, ICs, magnetic materials, etc.)

- Applications and Emerging Technology Trends (which may be used across many products and are enabled by many components)

Fig. 1 provides a 3D visualization of the power technology roadmap structure. The power technology roadmap cube ("PTR Cube") shows how each of the technology, component, and application segments intersect and overlap, describing the dependency between multiple cross segments.

A dedicated segment to address the component facet of the 
PTR cube was introduced in the 2017 PTR report. In earlier roadmaps, this facet was largely addressed through the webinar coverage.

To gather data from a broad range of experts, a series of webinars were conducted between January 2016 and February 2017. The webinars covered a wide range of power conversion topics loosely grouped into Application Trends, Component Technologies, Emerging Technologies and Power Supply \& Converter Trends. These presentations are listed below:

Application Trends

- Synergies Between Power Electronics and Energy Harvesting

- An Overview of Wireless Power Transfer and Standards

- Power and Sensor Devices Driving Automotive Semiconductor Applications

- iNEMI 2017 Energy Storage Roadmap - A Summary Component Technologies

- Trends in High-Frequency Magnetics and Power Supply Design

- Wide Bandgap Power Devices: Die Size Shrinking and Its Impact on Power Delivery Architecture

- GaN Power ICs and the High Frequency Eco-System

- SiC Power MOSFETs and Applications Status in 2016

- Technology Trends and Advances in Multilayer Chip Ceramic (MLCC) and Metallized Polypropylene Film Capacitors

Emerging Technologies

- Significant Developments and Trends in 3D Packaging with Focus on Embedded Substrate Technologies

- Nanofluids for Electronic Cooling

Power Supply and Converter Trends

- Present and Projected Safety-Regulatory and Compliance Requirements for Power Conversion and Power Supplies

- It's all about the insulation-Choosing the best digital isolator

The presentations were from OEMs, suppliers, technologists, research labs, and academics. These presented snapshots of today's state-of-the-art in power conversion technology, what the end customers are expecting in the next few years, and how the component technology is changing.

The webinars, including the question and answer segments, were recorded to allow the segment teams to review the presentations for estimating trends for each product. The recorded material is available as part of the electronic copy of the roadmap report. The webinars add much to the presentation materials as the listener can hear and understand the context and the subtext of the original presentation in the speaker's voice.

For the second part of the roadmap process, the core team and the volunteers divided into four segment teams. Each team is responsible for a different type of product (Power Supply and Converter Technology), chosen as representatives of the overall market:

- Ac-dc front-end power supplies (200 W-2000 W)

- External ac-dc power supplies (10 W-100 W)

- Isolated dc-dc converters (100 W, regulated)

- Non-isolated dc-dc converters (sub-divided into the stan-
TABLE I

Application and Technology Coverage

\begin{tabular}{|c|c|c|}
\hline $\begin{array}{l}\text { Application } \\
\text { Segments }\end{array}$ & $\begin{array}{l}\text { Component } \\
\text { Technologies }\end{array}$ & $\begin{array}{l}\text { Emerging } \\
\text { Technologies }\end{array}$ \\
\hline Automotive & PWM Controllers & Magnetics \\
\hline Computing & Low and Mid & Integrated \\
\hline Consumer & Voltage MOSFETs & Magnetics \\
\hline Lighting & IGBTs & 3D Power \\
\hline Medical & High Voltage & Packaging \\
\hline Motor Control & MOSFETs and GaN HEMTs & Additive \\
\hline Portable Charging & SiC Devices & Manufacturing \\
\hline Energy Harvesting & Passive Components & Nanofluids \\
\hline
\end{tabular}

dard non-isolated dc-dc and power supply in a package (PSiP) converters)

For each, the group made their best assessments of the technologies and metrics to track. A significant effort was made to streamline the survey questions (for both the online survey and the more detailed trends tables) to allow ease of data entry.

The online survey was created and sent out to the PSMA mailing list for responses. After the online survey closed, each segment team examined the results as they applied to their focused power supply design segment. Conference calls and questionnaires were used to gather inputs from other stakeholders. The consolidated results were then captured in a series of defined tables, which formed the basis of the trend tables. These tables convey the main quantitative substance of the report.

In the third part of the roadmap process, the application and technology commentaries provide windows into understanding key issues of the end applications and important technologies. Various industry leaders contributed articles on the general trends, key metrics, key market drivers, and challenges of each application segment. TABLE I lists the covered areas for applications, component technologies and emerging technologies.

\section{APPLICATIONS}

Power Electronics, like any other technology, is responsive to the needs of end applications in which it is embedded. Since power technology in one form or other is an integral part of any electronic system, the applications range for power technology is very diverse. In this section, the trends in end applications and their impact on power technology are covered.

The application trend overviews are written by a diverse group of experts representing power supply manufacturers, semiconductor manufacturers and research institutes. Experts were provided a simple template to express their views but were also encouraged to forge their own path and modify as they deemed necessary. The application segment overviews are intended to complement more in-depth and focused information found in the other sections of the PTR report. Topics that are covered include: automotive, computing, consumer, lighting, medical, motor control, and portable charging. This year energy harvesting segment made a debut keeping up with changing trends in power electronics. 
TABLE II

Automotive Safety Features

\begin{tabular}{|c|c|}
\hline Active Safety & Passive Safety \\
\hline Anti-Lock Brakes & Seat Belts \\
\hline Traction Control & Air Bags \\
\hline $\begin{array}{l}\text { Active Suspension and Electronic } \\
\text { Stability Control }\end{array}$ & Collapsible Steering Column \\
\hline Lane Departure Warning/Lane Assist & $\begin{array}{l}\text { Passenger Compartment Crumple } \\
\text { Zones }\end{array}$ \\
\hline $\begin{array}{l}\text { Emergency Brake Assist/Collision } \\
\text { Avoidance }\end{array}$ & Head Impact \\
\hline Pedestrian Avoidance & \\
\hline
\end{tabular}

The template followed by all the contributors includes the following sections:

- Introduction-A high level introduction to (or overview of) the application segment.

- Marker Drivers - Identification of two to three key application areas that are having largest impact on the whole segment and the implications for power electronics.

- Key Metrics - Identification of important power electronics metrics or specifications and how they are driving power electronics evolution for the segment.

- Trends - Identification of end use trends or disruptive forces that impact the application segment.

- Challenges - Discussion of the biggest challenges for power electronics industry and its components in the applications segment.

\section{A. Automotive Applications}

Worldwide initiatives to reduce emissions and improve active and passive safety (as shown in TABLE II) were identified as key market drivers. Lower battery costs, higher consumer acceptance and wider availability of charging infrastructure are the factors driving growth in electrical vehicle adaption. Driver comfort and convenience features for infotainment, lighting and connectivity are also driving power electronics growth in automotive field.

Choice of voltage rails, EMI standards and standby power drain were some of the key metrics identified. Key trends included enhanced safety features such as automatic braking, enhanced illumination and lighting, move to higher voltage rails and increased efficiency. EMI immunity and controlling emissions as the systems get more complex was the major challenge identified.

\section{B. Computing Applications}

For the datacenter market, hyperscale and hyperconvergence are identified as the overarching trends. Energy efficiency improvement, lower power consumption and use of standardized hardware are the key market drivers for power technologies. Power Usage Effectiveness (PUE) and its reciprocal Data Center Infrastructure Efficiency (DCIE) remain the key metrics.
TABLE III

European CoC Active Mode Efficiency Criteria

\begin{tabular}{ccc}
\hline \hline \multirow{2}{*}{$\begin{array}{c}\text { Rated Output Power } \\
\left(\mathrm{P}_{\mathrm{no}}\right)\end{array}$} & \multicolumn{2}{c}{$\begin{array}{c}\text { Minimum Efficiency in Active Mode at } \\
10 \% \text { load of full rated output current }\end{array}$} \\
\cline { 2 - 3 } & Tier 1 & Tier 2 \\
\hline $0.3<\mathrm{W}<1$ & $\geq 0.500 * \mathrm{P}_{\text {no }}+0.046$ & $\geq 0.500 * \mathrm{P}_{\text {no }}+0.060$ \\
\hline $1<\mathrm{W}<49$ & $\geq 0.0626 * \ln \left(\mathrm{P}_{\mathrm{no}}\right)+$ & $\geq 0.071 * \ln \left(\mathrm{P}_{\mathrm{no}}\right)-$ \\
& 0.546 & $0.00115 * \mathrm{P}_{\mathrm{no}}+0.570$ \\
\hline $49<\mathrm{W}<250$ & $\geq 0.790$ & $\geq 0.790$ \\
\hline \hline
\end{tabular}

The growth in hyperscale architectures is creating a trend away from proprietary hardware. Also, growth in the storage market has highlighted the need for capacity and speed. Achieving the right balance between the cost and performance remains the primary challenge for computing power technologies.

\section{Consumer Applications}

The consumer applications commentary focused on USB-PD Type-C connector and its impact on charging of consumer devices such as smartphones, tablets and Notebook PCs. The market drivers are quick-charging technologies, higher power level requirements and need for universal compatibility. Key metrics are the regulatory requirements for active mode efficiency and no-load power.

The main trends in this area are migration to type- $C$ connector for USB Power Delivery at higher power levels and corresponding need for new topologies that lead to higher power density of travel adapters. Efficiency performance of the acdc converters (as listed in TABLE III), and consolidation of the quick-charging technologies remain the key challenges.

\section{Energy Harvesting}

Examples of different energy harvesting sources are shown in Fig. 2.

The need for low power IoT devices to become self-powered or extend their battery life using energy harvesting is addressed. The explosive growth in IoT devices and the concerns about their availability due to battery life are the key market drivers for energy harvesting. Need for new metrics at system level in this emerging area is highlighted. One of those is defining behavior of power conversion circuits at very light and sporadic loads.

Trends in various sub-segments such as transducers, storage devices, PMICs, Magnetics, Capacitors and Low power sensing and processing are identified. Key challenges for energy harvesting are: limited and sporadic availability of ambient energy, need for miniaturization and related packaging challenges, and system level optimization.

\section{E. LED Lighting Applications}

LED lighting applications continue their penetration per Fig. 3. Applications covered include (a) retrofit residential, (b) ret- 


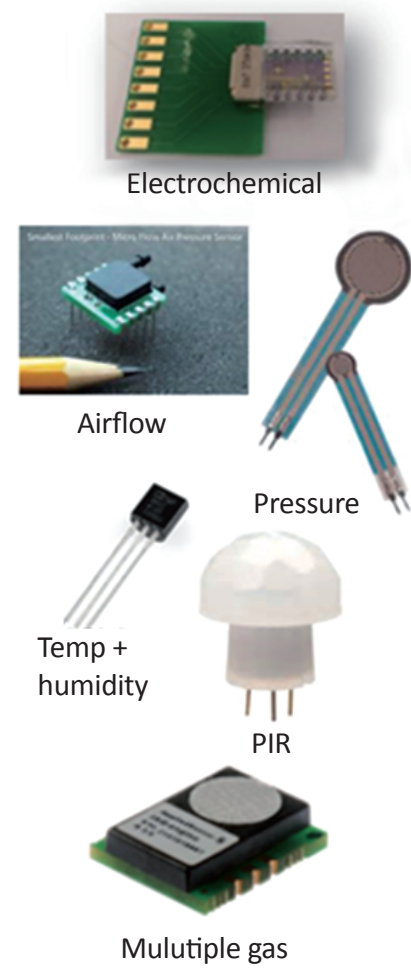

Fig. 2. Examples of energy harvesting sources.

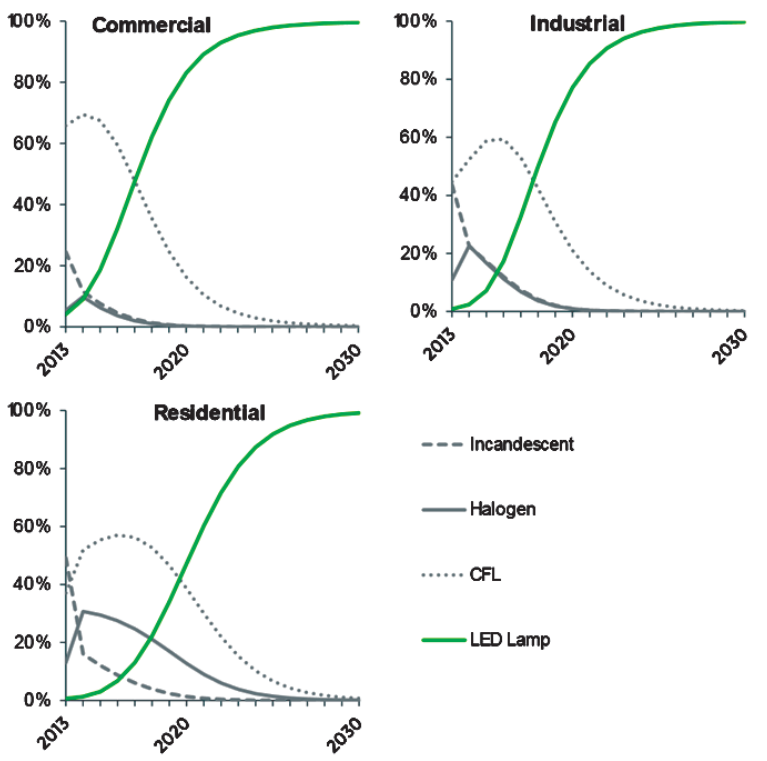

Fig. 3. Projected growth in LED lighting market-share (Source: US DoE, August 2014).

rofit industrial/commercial and (c) new constructions. Cost is a market driver for (a) and (c), while ease of installation is the driver for (a) and (b) and performance is the driver for (b) and (c). Some of the key metrics include operating life/reliability, compatibility, standby power, efficiency, THD/PF, and quality of light.

Key trends include selective transition from isolated to non-isolated LED drivers, single-stage topologies, selective use of PFC front-end, lower component count and deeper dimming. Some

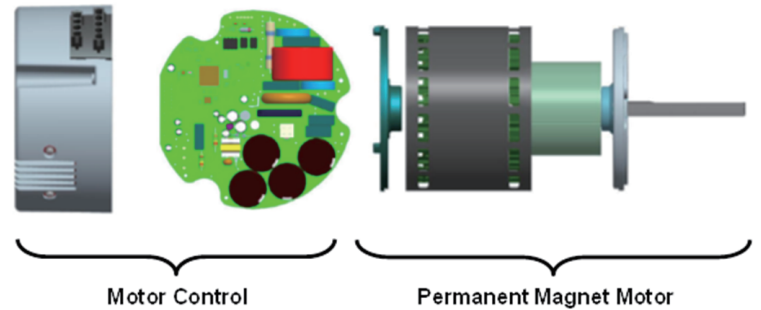

Fig. 4. Typical residential HVAC integrated motor drive.

of the challenges include flicker reduction and lower acoustic noise and compatibility for T-lamp replacement.

\section{F. Medical Applications}

The drivers for growth of power electronics in medical applications are identified as the aging population and advances in medical electronics to serve their healthcare needs. In addition, more stringent compliance standards are also expected to shape the evolution of medical power electronics.

Development of artificial intelligence, deep learning and machine learning; 3D medical printing; and growing popularity of surgical robotics are some of the major trends. The challenges include the trade-offs between needs for higher density and safety requirements; changes in EMC as legislated by IEC60601-12 ; reducing development costs while meeting safety and regulatory regime; and improving active mode and standby efficiency of home healthcare devices as they proliferate further.

\section{G. Motor Control}

The need for high-efficiency motor drive systems is highlighted given their total share $(\sim 40 \%)$ of world-wide energy consumption. An example is shown in Fig. 4. The drivers include need for efficient variable speed control, optimized performance for a given application and cost reductions.

Key trends include higher level of electronic component integration and sophistication of software to simplify hardware and give more options to consumers, including connectivity. Major challenges include thermal management with higher power density and component life/reliability with more constrained environments.

\section{H. Portable Charging}

Portable charging of single-cell (low and high power) and multi-cell Li-ion batteries is covered. The main drivers are high-current charging and universal charge compatibility, with USB Power Deliver gaining traction across multiple power levels per the example of Fig. 5. Additional driver is the proliferation of other mobile devices. Key metrics include energy density, cost, temperature capability, and reliability.

The trends in portable charging consist of high input voltage chargers; incremental converter efficiency improvements; parallel chargers; low-voltage, high-current chargers; and buckboost architecture for universal compatibility of multi-cell chargers. The main challenge is in effectively addressing the end 


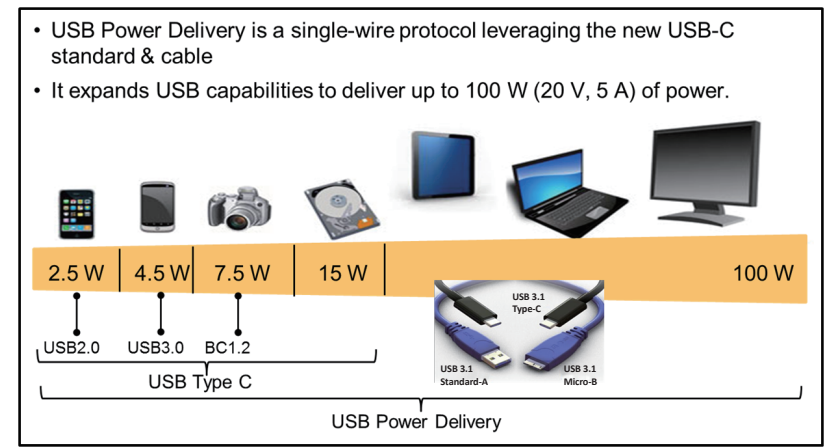

Fig. 5. USB power levels.

consumer's battery life anxiety, while providing ever-growing functionality. Adding intelligence and flexibility while increasing the charge current and reducing the temperature is another significant challenge.

\section{COMPONENTS}

High-frequency, switch-mode, power-conversion equipment functions by controlling the flow of energy in discrete time intervals. This requires components and devices that store that energy along with components and devices that allow the energy to flow from one part of the circuit to another at the appropriate time. Magnetic and capacitive devices are the primary energy storage technologies (batteries are not addressed in this section). Semiconductor switches and controllers control the energy flow.

Incremental, and occasionally significant, improvements in components and devices continue to enable the ever-increasing density and efficiencies of power conversion equipment. The industry may be on the cusp of another step change as wide band gap (WBG) semiconductor switches become commercialized. These devices offer the potential of much higher switching frequencies, and therefore density, while maintaining or even improving efficiencies. These potential improvements are not without their challenges, and impact all components, including the semiconductor switches, the energy storage devices and the controllers.

\section{A. Wide Bandgap (WBG) Technology Trends}

For power technology applications, the two applicable WBG devices are Gallium Nitride (GaN) and Silicon Carbide ( $\mathrm{SiC})$ switches. Fig. 6 illustrates the frequency/power level space these new devices are carving out in various applications.

\section{1) GaN Devices}

The GaN power switches are relatively new and are getting utilized in niche applications such as datacenter power and specialty high efficiency adapters. By reducing switching losses significantly, GaN switches improve efficiency and enable higher power density conversion. Another highlighted benefit of GaN devices is low and linear output capacitance, which enables shorter dead-time in ZVS applications - leading to higher available duty cycle and lower rms currents and/or higher frequency operation.

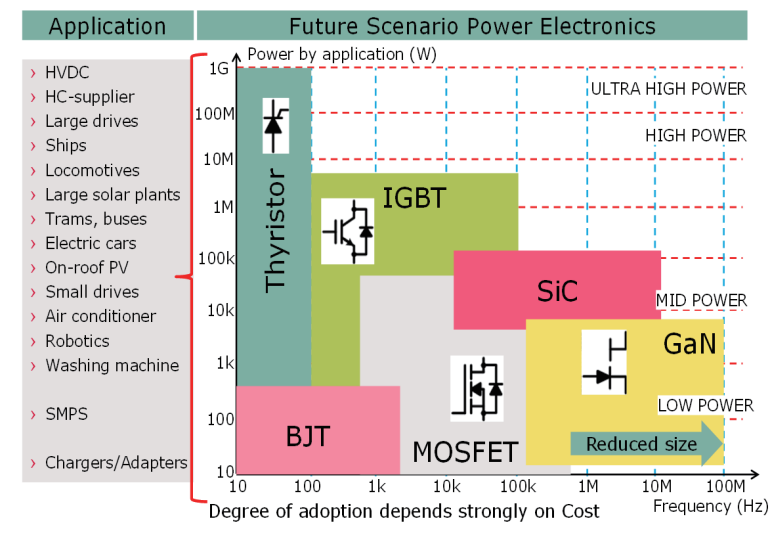

Fig. 6. Switching power device application space.

Performance of GaN switches is measured by 3 Figures of Merit (FOM) shown below. In all of the FOM, GaN shows superior performance to Silicon Superjunction FETs.

- $\mathrm{R}_{\mathrm{DS}(\mathrm{ON})} \mathrm{x}$ Qoss-about 10x improvement

- $\mathrm{R}_{\mathrm{DS}(\mathrm{ON})} \times \mathrm{Q}$ Qrr-about 10x-100x better

- $\mathrm{R}_{\mathrm{DS}(\mathrm{ON})} \times \mathrm{Qg}-$ about $12 \mathrm{x}$ improvement

Identifying and employing topologies that take advantage of these FOMs is key to rapid adaptation of $\mathrm{GaN}$ devices in midhigh power applications.

The major challenges for GaN devices include cost and reliability. While cost projections indicate rapid drop as volumes increase, the reliability issue is being addressed by industry-wide standards development groups.

\section{2) $\mathrm{SiC}$ Devices}

Compared to $\mathrm{GaN}$ devices, $\mathrm{SiC}$ devices have been around longer, but the SiC MOSFET has gained maturity and wider acceptance in recent years. Most of the offerings are planar DMOSFETs, with some trench device availability. The market drivers for $\mathrm{SiC}$ adaption are the need for higher power density and (often) lower cost due to high switching frequency operation.

$\mathrm{SiC}$ devices are typically used for $1200 \mathrm{~V}$ applications, though some lower voltage $(650 \mathrm{~V}$ and $900 \mathrm{~V})$ applications are also starting to use $\mathrm{SiC}$ devices. One of the trends is reduction in specific $\mathrm{R}_{\mathrm{DS}(\mathrm{ON})}$ of the devices - which is in the range of 2.5 $\mathrm{m} \Omega \cdot \mathrm{cm}^{2}$ — significantly lower than Silicon.

While the market drivers for $\mathrm{SiC}$ remain strong (due to growth in Electric Vehicles and Renewable Energy power conversion), the key challenge remains the device cost. Also, the end users' lack of familiarity with high frequency designs or other practical issues such as EMI concerns could limit the growth of the $\mathrm{SiC}$ devices.

\section{B. Passive Component Trends for High Frequency}

Improvements in WBG devices are also accompanied by improvements in magnetic and capacitors while setting new challenges for those same device technologies.

Some of the improvements are captured in depth in Section VI below. Others are discussed, and will continue to be discussed in industry workshops organized by the PSMA. Topics such as core materials, characterization and modeling under 
realistic circuit operation has been covered in the 2016 [2] and 2017 workshops [3]. Two workshops are also planned for March 2018 in conjunction with the APEC 2018 conference; one will address magnetics winding losses [4] while the other will address capacitor technologies [5].

Space does not permit detailed discussion of these topics in this paper. Instead readers are encouraged to contact the PSMA committees responsible for the workshops for further information.

\section{Power Supply And Converter TRends}

The roadmap tracks four power supply and converter product segments. These segments are unchanged from recent reports, which facilitates reporting on long term trends. One of the segments, ac-dc front-end power supplies, can be traced back to the original roadmap in 1994. The scope of the dc-dc segments has evolved over time. External ac-dc power supplies were added later.

These tables convey the main quantitative substance of the report.

\section{A. Ac-Dc Front-End Power Supplies}

This segment covers ac-dc power supply technology from $200 \mathrm{~W}$ to $2000 \mathrm{~W}$. While computer servers tend to drive many of the technological advancements, the questions are structured to gain a view beyond front-end power supplies for servers and include perspective on trends in telecom, industrial and medical applications.

The survey only considers power supplies with a single, main output, usually in the range of $12 \mathrm{~V}$ to $48 \mathrm{~V}$. The power supplies in question:

- Will typically be enclosed in a metal box at higher power level, but may be open frame in power levels closer to the 200 W lower limit;

- Can be hot-swapped, pluggable designs or fixed-chassismount in style;

- Can have an internal fan, especially at higher power levels, but may also be system cooled. Convection ratings are possible at the lower power levels and as efficiency levels increase, but the majority of power supplies in this range are still cooled by moving air.

Because the power range is broad, some questions have been split in two to separately address the 200-600 W and 600-2000 $\mathrm{W}$ spaces.

\section{1) General Observations}

Some disparate opinions on priorities for Telco applications were noted with some contention between the relative importance of cost and reliability in a rapidly changing, yet highly competitive industry.

The emergence of $380 \mathrm{Vdc}$, and similar, high voltage distribution in high-end computing and telecommunications environments was noted in prior roadmaps and continues to be mentioned in the surveys. However, adoption to date has remained low.
TABLE IV

Ac-Dc Front-End Trends (General)

\begin{tabular}{|c|c|c|c|c|}
\hline Parameter/Metric & $\begin{array}{l}2019 \text { Est. } \\
\text { (PTR 2015) }\end{array}$ & 2017 & 2019 & 2021 \\
\hline \multicolumn{5}{|l|}{$\begin{array}{l}\text { Peak Efficiency@ } 48 \text { V Output } \\
\text { at any load (Eff } \%)\end{array}$} \\
\hline Most Economical Models & $94.0 \%$ & $95.5 \%$ & $95.5 \%$ & $96.0 \%$ \\
\hline Highest Practical Models & $96.5 \%$ & $96.5 \%$ & $96.5 \%$ & $97.0 \%$ \\
\hline Leading Edge Models & $97.5 \%$ & $97.3 \%$ & $97.5 \%$ & $98.0 \%$ \\
\hline \multicolumn{5}{|l|}{$\begin{array}{l}\text { Peak Efficiency@12 V Output } \\
\text { at any load (Eff } \%)\end{array}$} \\
\hline Most Economical Models & $93.0 \%$ & $93.5 \%$ & $94.0 \%$ & $94.0 \%$ \\
\hline Highest Practical Models & $96.5 \%$ & $96.0 \%$ & $96.1 \%$ & $96.3 \%$ \\
\hline Leading Edge Models & $97.0 \%$ & $96.3 \%$ & $96.3 \%$ & $96.5 \%$ \\
\hline \multicolumn{5}{|l|}{ Efficiency Profile vs. Load } \\
\hline Flat efficiency profile over load range & $40 \%$ & $30 \%$ & $32 \%$ & $35 \%$ \\
\hline Efficiency Optimized for Half-Load & $30 \%$ & $45 \%$ & $43 \%$ & $40 \%$ \\
\hline Efficiency Optimized for Full-Load & $10 \%$ & $15 \%$ & $15 \%$ & $15 \%$ \\
\hline \multirow[t]{2}{*}{ Don't Care } & $20 \%$ & $10 \%$ & $10 \%$ & $10 \%$ \\
\hline & $100 \%$ & $100 \%$ & $100 \%$ & $100 \%$ \\
\hline \multicolumn{5}{|l|}{$\begin{array}{l}\text { Power Management Interface } \\
\text { Technology }(\%)\end{array}$} \\
\hline No Power Management Interface & $10 \%$ & $8 \%$ & $6 \%$ & $4 \%$ \\
\hline Discrete Digital and Analog Signals Only & $15 \%$ & $15 \%$ & $12 \%$ & $10 \%$ \\
\hline Serial Bus Interface Only & $40 \%$ & $37 \%$ & $42 \%$ & $48 \%$ \\
\hline \multirow[t]{2}{*}{$\begin{array}{l}\text { Mix of Discrete Signals and Serial } \\
\text { Communication Bus }\end{array}$} & $35 \%$ & $40 \%$ & $40 \%$ & $38 \%$ \\
\hline & $100 \%$ & $100 \%$ & $100 \%$ & $100 \%$ \\
\hline
\end{tabular}

277 Vac and 480 Vac operation continues to be a bigger factor, expanding beyond LED drivers to Datacenters and other applications.

Efficiency levels continue to trend upwards but at a slower rate as other system level approaches are utilized for energy conservation.

Power Factor Correction (PFC) switching frequencies remain relatively low, typically below $150 \mathrm{kHz}$. But commercialization of GaN offers the potential to increase the frequency where the higher component cost can be managed.

LLC converters continue to gain share in the Dc-Dc section of the power supply, and switching frequencies may also trend upward here as $\mathrm{GaN}$ becomes suitable.

The momentum behind the adoption of digital and mixed-signal controllers continues unabated for both PFC and Dc-Dc stages.

\section{2) Trend Tables}

The entirety of the report and this segment is written by experts in the field, thereby bringing value to the power conversion community. However, much of the report is qualitative and many come to the report seeking quantitative assessment. TABLE IV and TABLE $\mathrm{V}$ in this section provide examples of that insight. Space permits only limited examples and the reader is referred to the full report for more detail. 
TABLE V

Ac-Dc Front-End Trends (Dc-Dc Stage)

\begin{tabular}{|c|c|c|c|c|}
\hline Parameter/Metric & $\begin{array}{l}2019 \text { Est. } \\
\text { (PTR 2015) }\end{array}$ & 2017 & 2019 & 2021 \\
\hline \multicolumn{5}{|l|}{ Primary Switch Technology (\%) } \\
\hline $\begin{array}{l}\text { Silicon MOSFET (including } \\
\text { SuperJunction) }\end{array}$ & $83 \%$ & $90 \%$ & $83 \%$ & $70 \%$ \\
\hline Silicon Carbide FET & $5 \%$ & $3 \%$ & $5 \%$ & $14 \%$ \\
\hline IGBT & $0 \%$ & $1 \%$ & $0 \%$ & $0 \%$ \\
\hline GaN FET & $10 \%$ & $5 \%$ & $11 \%$ & $15 \%$ \\
\hline \multirow[t]{2}{*}{ Other (e.g. GaAs FET) } & $2 \%$ & $1 \%$ & $1 \%$ & $1 \%$ \\
\hline & $100 \%$ & $100 \%$ & $100 \%$ & $100 \%$ \\
\hline \multicolumn{5}{|l|}{ Transformer Winding Technology (\%) } \\
\hline $\begin{array}{l}\text { Traditional Wire And Foil Wound } \\
\text { On A Bobbin (Primary \& Second- } \\
\text { ary) }\end{array}$ & $25 \%$ & $25 \%$ & $20 \%$ & $18 \%$ \\
\hline \multirow{2}{*}{$\begin{array}{l}\text { At Least One Flat Or Planar } \\
\text { Winding Of Any Construction Or } \\
\text { Material }\end{array}$} & $75 \%$ & $75 \%$ & $80 \%$ & $82 \%$ \\
\hline & $100 \%$ & $100 \%$ & $100 \%$ & $100 \%$ \\
\hline \multicolumn{5}{|l|}{ Inductor Winding Technology (\%) } \\
\hline $\begin{array}{l}\text { Traditional Wire And Foil Wound } \\
\text { On A Bobbin }\end{array}$ & $65 \%$ & $65 \%$ & $50 \%$ & $45 \%$ \\
\hline $\begin{array}{l}\text { At Least One Flat Or Planar } \\
\text { Winding Of Any Construction Or } \\
\text { Material }\end{array}$ & $30 \%$ & $30 \%$ & $40 \%$ & $40 \%$ \\
\hline \multirow[t]{2}{*}{$\begin{array}{l}\text { Topology requires no separate } \\
\text { output inductor }\end{array}$} & $5 \%$ & $5 \%$ & $10 \%$ & $15 \%$ \\
\hline & $100 \%$ & $100 \%$ & $100 \%$ & $100 \%$ \\
\hline
\end{tabular}

\section{B. Ac-Dc External Power Supplies}

External ac-dc power supplies are commonly known as ac adapters. They are widely used for consumer and mobile products; including cell phones, tablets, laptop computers, portable DVD players, set-top boxes, printers, display monitors, and smaller flat-screen televisions. The advantages include weight and size reduction of the main product, safety (due to keeping the mains voltage out of the end product and electrically isolating it), reducing EMI problems within the product, and allowing multiple sources for the adapters. Along with the advances in technology of the end products, there have been consistent improvements in the technology of the ac adapters themselves fueled by end-user demands for smaller, more efficient, and more reliable products and by regulatory agencies worldwide in their pursuit of energy conservation. Due to the consumer nature of adapters, the trends' adoption rate has been tempered by the need to keep the total cost of new solutions nearly the same as existing solutions.

\section{1) General Observations}

The power levels of phone chargers are increasing driven by the higher capacity batteries and the need for fast charging. At the same time, laptops are becoming more energy efficient and power levels in these applications are stable, or even falling.

Flybacks remain the topology of choice below $100 \mathrm{~W}$, but spread across hard-switching, quasi-resonant and active clamp
TABLE VI

AC-DC EXTERNAL TRENDS

\begin{tabular}{lcccc}
\hline \hline Parameter/Metric & $\begin{array}{c}\text { 2019 Est. } \\
\text { (PTR 2015) }\end{array}$ & 2017 & 2019 & 2021 \\
\hline Output connector (\%) (<15 W) & & & \\
$\quad$ Permanent Cable & $29 \%$ & $21 \%$ & $17 \%$ \\
USB Type A & $17 \%$ & $17 \%$ & $15 \%$ \\
USB Type B & $16 \%$ & $18 \%$ & $17 \%$ \\
USB Type C & $17 \%$ & $23 \%$ & $29 \%$ \\
Other & $22 \%$ & $22 \%$ & $22 \%$ \\
& $\mathbf{1 0 0 \%}$ & $\mathbf{1 0 0 \%}$ & $\mathbf{1 0 0 \%}$ \\
\hline
\end{tabular}

\begin{tabular}{lcccc}
\hline $\begin{array}{l}\text { Output connector (\%) } \\
\text { (15-65 W) }\end{array}$ & & & & \\
Permanent Cable & & $43 \%$ & $42 \%$ & $33 \%$ \\
USB Type A & & $10 \%$ & $6 \%$ & $4 \%$ \\
USB Type B & & $6 \%$ & $10 \%$ & $8 \%$ \\
USB Type C & $30 \%$ & $22 \%$ & $14 \%$ \\
Other & $\mathbf{1 0 0 \%}$ & $\mathbf{1 0 0 \%}$ & $\mathbf{1 0 0 \%}$ \\
& & & & \\
\hline Peak Efficiency - (<30 W Models) & & & & \\
(Eff\%) & $79 \%$ & $76 \%$ & $79 \%$ & $79 \%$ \\
Most Economical & $88 \%$ & $88 \%$ & $88 \%$ & $88 \%$ \\
Highest Practical & $93 \%$ & $92 \%$ & $93 \%$ & $95 \%$ \\
$\quad$ Leading Edge & & & & \\
\hline Peak Efficiency - (30-100 W & & & & \\
Models) (Eff\%) & $86 \%$ & $85 \%$ & $86 \%$ & $87 \%$ \\
Most Economical & $91 \%$ & $90 \%$ & $91 \%$ & $92 \%$ \\
Highest Practical & $94 \%$ & $93 \%$ & $94 \%$ & $95 \%$ \\
$\quad$ Leading Edge & & & & \\
\hline No Load Power Consumption (mW) & 150 & 200 & 150 & 90 \\
Most Economical & 30 & 30 & 30 & 20 \\
Lowest Practical & 5 & 10 & 5 & 5 \\
Leading Edge & & & & \\
\hline \hline
\end{tabular}

variants. Above $100 \mathrm{~W}$, LLC topologies are gaining momentum.

As power levels increase, integration of active devices is increasing to improve power density. GaN- and SiC-based solutions are being pursued in this area but have not yet been broadly adopted as costs continue to be addressed.

\section{2) Trend Tables}

TABLE VI provides an example and readers are recommended to view the entire report for additional quantitative data.

\section{Isolated Dc-Dc Converters}

Demand for isolated dc-dc converter modules continues to be dominated by applications in the converged computing and telecommunications market segment as the integration of voice and data communication capabilities into the internet backbone is almost complete and in a steep commoditization trend. Data center applications require system-level solutions that optimize size and efficiency and are driving the proliferation of digital interface control and real-time adaptability of the various versions of the intermediate bus architecture. Industrial, military, 
aerospace, and other applications remain significantly smaller, yet still drive industry segmentation with parameters like input voltage range, packaging, and environmental requirements.

While the power levels can vary broadly, the parameters captured in this survey focus on $100 \mathrm{~W}$ isolated converters to allow consistent trend-tracking from year to year. These trends are believed to be reasonably representative and can be scaled to the broader space.

\section{1) General Observations}

Converter packages are expected to continue to shrink, with the market tilting in favor of smaller packages. In the next five years, no single package size will be dominant; buyers will find more options at the same power level, but with a wide variety of features and functionality.

More command and control ability is added to existing sizes to increase value at existing power densities.

Soft switching topologies and fixed-frequency designs are expected to dominate the converter market in 2019 as manufactures leverage advancements in FET technologies and increasing levels of device integration.

The demand for high voltage ( 270 or $380 \mathrm{~V}$ input) converters by 2019-2021 is expected to noticeably increase due to multiple market segments leveraging the inherent benefits of HVDC distribution architectures. The traditional (wide) telecom input range continues to be popular and widely used.

\section{2) Trend Tables}

TABLE VII provides an example and readers are recommended to view the entire report for additional quantitative data.

\section{Non-Isolated Dc-Dc Converters}

Non-isolated dc-dc power converters make up one of the largest segments in power conversion architecture. The converters are used in server, networking, telecom, industrial, consum$\mathrm{er}$, and automotive applications for powering the intermediate bus and/or final applications where low voltage and higher current loads are used. For safety reasons, non-isolated converters almost universally have a maximum input voltage of less than $100 \mathrm{~V}$. Telecom, networking, and industrial applications have input voltages more in the $12 \mathrm{~V}$ to $48 \mathrm{~V}$ range. The output voltage is typically at or below $5 \mathrm{~V}$. Exceptions are sensors, analog IC loads, specialty and motor control, or emerging applications with output voltages as high as $12 \mathrm{~V}$ or applications that require negative voltage. In most applications where non-isolated dcdc converters are used, the digital loads are CPU, GPU, memory chips, DSP, FPGA, and ASICs that require fast transient response with minimal voltage deviation. These lower voltage converters have outputs in the range of $0.5 \mathrm{~V}$ to $2.5 \mathrm{~V}$ with load currents varying from a few amps to hundreds of amps. These are the last stages in the power conversion process and define the term point of load (POL).

\section{1) General Observations}

Output voltages provided by non-isolated converters continue to drop about $50 \mathrm{mV}$ per year while the load currents and power are increasing about $10 \%$ per year. As the trend tables and sur-
TABLE VII

ISOLATED DC-DC TRENDS

\begin{tabular}{lcccc}
\hline \hline Parameter/Metric & $\begin{array}{c}\text { 2019 Est. } \\
\text { (PTR 2015) }\end{array}$ & 2017 & 2019 & 2021 \\
\hline $\begin{array}{l}\text { Input Voltage Range (\%) } \\
\quad \text { Telecomm Wide Range (36-75 V, }\end{array}$ & $35 \%$ & $56 \%$ & $45 \%$ & $30 \%$ \\
$\begin{array}{l}36-72 \mathrm{~V}, \text { etc.) } \\
\text { Narrow Range (48 V } \pm 5 \% \text { Or }+5 \%\end{array}$ & $32 \%$ & $28 \%$ & $32 \%$ & $29 \%$ \\
/-10\% ) & $9 \%$ & $11 \%$ & $10 \%$ & $12 \%$ \\
24 or 28 & $23 \%$ & $5 \%$ & $13 \%$ & $29 \%$ \\
270 or 380 & & $\mathbf{1 0 0 \%}$ & $\mathbf{1 0 0 \%}$ & $\mathbf{1 0 0 \%}$ \\
& & & & \\
\hline
\end{tabular}

\begin{tabular}{lcccc}
\hline $\begin{array}{l}\text { Expected Maximum Output Cur- } \\
\text { rent (A) }\end{array}$ & & & & \\
$\quad$ Quarter Brick & 135 & 64 & 76 & 89 \\
Eighth Brick & 83 & 37 & 44 & 53 \\
Sixteenth Brick & 49 & 17 & 21 & 26 \\
\hline
\end{tabular}

\begin{tabular}{lcccc}
\hline $\begin{array}{l}\text { Expected Efficiency-most ad- } \\
\text { vanced (Eff\%) }\end{array}$ & & & & \\
48Vin - 3.3Vout (regulated) & $94 \%$ & $88 \%$ & $89 \%$ & $91 \%$ \\
48Vin - 12Vout (regulated) & $96 \%$ & $92 \%$ & $94 \%$ & $97 \%$ \\
48Vin - 12Vout (unregulated) & $98 \%$ & $92 \%$ & $95 \%$ & $95 \%$ \\
380Vin - 12Vout (regulated) & $97 \%$ & $92 \%$ & $96 \%$ & $96 \%$ \\
380Vin - 12Vout (unregulated) & $98 \%$ & $92 \%$ & $96 \%$ & $96 \%$ \\
\hline Power Management Interface & & & & \\
Technology (\%) & $30 \%$ & $51 \%$ & $44 \%$ & $37 \%$ \\
None & $27 \%$ & $13 \%$ & $20 \%$ & $23 \%$ \\
I2C & $39 \%$ & $16 \%$ & $30 \%$ & $40 \%$ \\
PMBus & $4 \%$ & $20 \%$ & $6 \%$ & $0 \%$ \\
Other & & $\mathbf{1 0 0} \%$ & $\mathbf{1 0 0} \%$ & $\mathbf{1 0 0} \%$ \\
& & & & \\
\hline
\end{tabular}

vey results show, many high-end boards now have power rails down to $0.5 \mathrm{~V}$.

After EMI, the survey respondents selected power density as the most important feature, followed by efficiency. Even though power density is in the top design criteria, the switching frequencies are predicted to remain stable at $600 \mathrm{kHz}$ to $2 \mathrm{MHz}$.

The number of PCB layers for a typical non-isolated converter design is increasing, with six or more layers becoming the dominant construction of most converters. Meanwhile, the number of PCB layers on discrete converter/ regulator on server boards has reached the twenties. To save space, most regulators have switched to non-standard QFN packages, with large areas under the package to remove heat and carry large load currents. For currents lower than 20 A, Power Supply in a Package (PSiP) and Power Supply on a Chip (PwrSoC) packaging technologies are considered cost-effective alternatives to the modules.

Although many respondents predict digital implementation of the control loop proliferating in the next five years, they still think a large majority of converters $(>60 \%)$ will continue using pure analog feedback control.

There is a strong interest in $48 \mathrm{~V}$ POL conversion, especially for high-power CPU/GPU type loads. As the high-end server power requirement per board is increasing, distribution losses with traditional $12 \mathrm{~V}$ architecture hurt efficiency. 
TABLE VIII

Non-IsOlated DC-DC TRENDS

\begin{tabular}{lcccc}
\hline \hline Parameter/Metric & $\begin{array}{c}\text { 2017 Est. } \\
\text { (PTR 2015) }\end{array}$ & 2017 & 2019 & 2021 \\
\hline $\begin{array}{l}\text { Input Voltage Range (Vin) (\% of } \\
\text { Total Market) }\end{array}$ & & & & \\
$\quad$ Above 14 V and below 54 V & $4.0 \%$ & $6.0 \%$ & $6.3 \%$ & $6.5 \%$ \\
Wide Range (3 V $<$ Vin $<13.2 \mathrm{~V})$ & $35.7 \%$ & $25.0 \%$ & $24.5 \%$ & $24.0 \%$ \\
12 V Narrow $(10.8 \mathrm{~V}<$ Vin $<13.2 \mathrm{~V})$ & $27.7 \%$ & $27.5 \%$ & $27.3 \%$ & $27.0 \%$ \\
$10-12 \mathrm{~V}$ Wide $(7.5 \mathrm{~V}<$ Vin $<13.2 \mathrm{~V})$ & $18.0 \%$ & $29.0 \%$ & $29.8 \%$ & $30.5 \%$ \\
$3.3-5 \mathrm{~V}(3 \mathrm{~V}<$ Vin $<6 \mathrm{~V})$ & $13.7 \%$ & $11.5 \%$ & $11.3 \%$ & $10.5 \%$ \\
Other & $1.0 \%$ & $1.0 \%$ & $1.0 \%$ & $1.5 \%$ \\
& $\mathbf{1 0 0 \%}$ & $\mathbf{1 0 0 \%}$ & $\mathbf{1 0 0 \%}$ & $\mathbf{1 0 0 \%}$ \\
\hline
\end{tabular}

Peak Efficiency (Typical Peak)

$($ Vin $=12 \mathrm{~V}$, Vout $=1.2 \mathrm{~V}$, Iout $=$

$60 \mathrm{~A})(\mathrm{Eff} \%)$

Most Economical

Highest Practical Performance

$\begin{array}{llll}86.7 \% & 86.8 \% & 87.3 \% & 88.3 \%\end{array}$

Leading Edge Performance

$92.3 \% \quad 90.8 \% \quad 91.3 \% \quad 92.3 \%$

\begin{tabular}{llll}
$94.7 \%$ & $92.3 \%$ & $93.0 \%$ & $93.7 \%$ \\
\hline
\end{tabular}

Power Management Interface

Technology (\% of Total Market)

$\begin{array}{llll}\text { No Power Management Interface } \quad 34.5 \% & 36.0 \% & 36.5 \% & 30.8 \%\end{array}$

Discrete Digital And Analog

Signals Only

$27.5 \% \quad 21.3 \% \quad 20.5 \% \quad 20.0 \%$

Serial Bus Interface Only

Mix Of Discrete Signals And

Serial Comm. Bus

$\begin{array}{llll}16.5 \% & 20.8 \% & 21.0 \% \quad 25.0 \%\end{array}$

$21.5 \% \quad 22.0 \% \quad 22.0 \% \quad 24.3 \%$

$100 \% \quad 100 \% \quad 100 \% \quad 100 \%$

Communication Protocol Type (\%

of Total Market)

$\begin{array}{lllll}\text { Customer Specific } & 1.3 \% & 3.0 \% & 2.3 \% & 2.3 \%\end{array}$

$\begin{array}{lllll}\text { Supplier Specific } & 11.3 \% & 23.0 \% & 22.5 \% & 21.0 \%\end{array}$

$\begin{aligned} & \text { Open Or Industry Std Bus (e.g. } \quad 76.0 \% \\ & \text { PMBus }^{\mathrm{TM}} \text { ) }\end{aligned} \quad 71.5 \% \quad 72.8 \% \quad 74.3 \%$

PMBus ${ }^{\mathrm{TM}}$ )

$\begin{array}{lllll}\text { Other Bus } & 11.3 \% & 2.5 \% & 2.5 \% & 2.5 \%\end{array}$

$100 \% \quad 100 \% \quad 100 \% \quad 100 \%$

A new market is surfacing that was formerly hidden in the "other" market category: automotive and industrial power. With engine control, infotainment, and newer Advanced Driver Assist (ADAS) features; these areas have transient requirements similar to server applications, but with $<10$ A current requirements.

\section{2) Trend Tables}

TABLE VIII provides an example and readers are recommended to view the entire report for additional quantitative data.

\section{EMERGING TeChNOLOGIES}

An important part of any Technology Roadmap is highlighting emerging technologies that could be significant to the industry. These technologies are not fully developed or in large volume production, but show promise as important game changers. This section features technology overviews written by industry experts in these fields. Two of the commentaries (3D packaging and additive manufacturing) focus on technologies that strive to increase power density to keep pace with increasing power demands of 3D digital circuits. Both include insight into the use of embedded components to shrink size, plus the ability to use additive manufacturing to print metal enclosures and heat sinks right in the laboratory. In addition, as densities increase, the need for smaller and more efficient thermal management devices continues to escalate. Liquid cooling is being implemented in a variety of mechanical configurations. The enclosed commentary highlights how the use of coolants with nanoparticles (nanofluid) can provide further improvements within a liquid-cooled system.

\section{A. Trends in 3D Packaging of Power Products}

Until recently, the packaging of power supplies was limited to what can be manufactured with machine and hand assembled multi-layer printed circuit boards with components on both sides. The emergence of embedded substrate technology was identified in the 2015 edition of the PTR [6] as having broad applicability to power supplies and converters. It provides the benefits of increased performance through lower parasitics, a smaller footprint, higher power density $\left(\mathrm{W} / \mathrm{cm}^{3}\right)$, and lower cost $\left(\$ / \mathrm{W} / \mathrm{cm}^{3}\right)$. Millions of units have been produced and shipped for everything from portable electronics to servers, automobiles, and industrial applications. However, in the majority of these products, only silicon semiconductor die are embedded. To continue to meet the needs of customers, it is essential the technology emerges that allows the cost-effective manufacture of embeddable Wide Band Gap (WBG) devices and power-capable capacitors and inductors.

The key market driver of this technology is to allow size and density improvements in the power converters as the loads of the power converter continue to shrink. While the size improvements will never scale with Moore's Law or the 'more than Moore' phenomenon, these techniques offer a path towards supporting the necessary power converter density improvements.

The biggest challenge is to find semiconductor, capacitor, inductor/transformer, and resistor companies to invest and market catalog products for 3D manufacturing; specifically, embedded substrates. Today, most will provide parts as custom designs for high-volume applications, and at a cost premium. The power industry can innovate faster with catalog available technology.

\section{1) Semiconductors}

There is now some maturity in the 3D packaging of semiconductor devices. Great progress has been made with both silicon and WBG devices manufactured for embedding or 3D assembly. The leading interconnect technologies are adhesives, solder, direct copper plating, and silver sintering. The embedded substrate designs are using a solder ball or other soldering technology for interconnection or are procuring die with copper terminations and directly plating to the die. The high-current products use either soldering to copper lead frames, plating to copper terminated die, or silver sintering. An emerging technology that is showing promise is Transient Liquid Phase Sintering (TLPS) [7], a liquid-assist sintering process during which a low melting point metal or alloy melts, surrounds, and diffuses into a different high-melting point metal. This system can be 

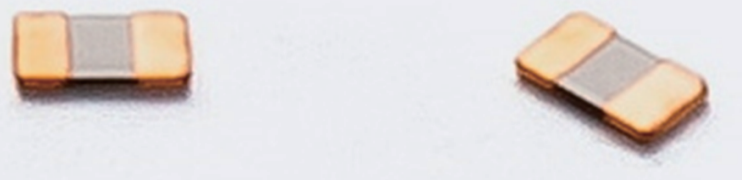

Fig. 7. Samsung embeddable capacitors $0.11 \mathrm{~mm}$ to $0.33 \mathrm{~mm}$ height.
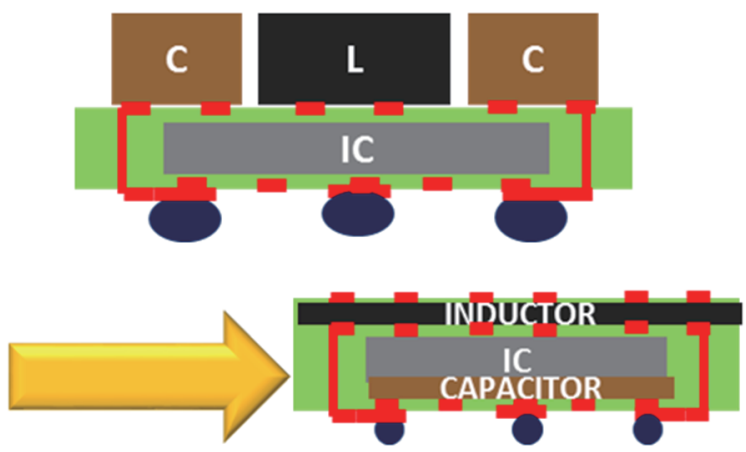

Fig. 8. Embedding of capacitor and inductor (Courtesy of Georgia Tech).

processed at low temperatures, but is capable of operating at the high melting point temperature of intermetallic compounds. $\mathrm{Cu}-\mathrm{Sn}$ joints have been demonstrated that retain shear strength to $\mathrm{T}>400{ }^{\circ} \mathrm{C}$. While many of the technologies are proven, the number of semiconductor or third-party companies willing to process die for 3D manufacture is still limited.

\section{2) Capacitors}

To further increase the density and decrease the size of 3D packaged power sources, it is essential that embeddable or stackable capacitors and inductors capable of higher currents and voltages become available. While several manufactures have been making custom capacitors in thin packages with copper termination, the first catalog parts designed for embedding just emerged in 2016. AVX has introduced its Ultra Thin (UT) series [8] with voltages up to $50 \mathrm{~V}$ at less than $0.35 \mathrm{~mm}$ thick. Samsung has introduced copper-terminated embeddable capacitors in case sizes from 0603 to 1005 , with values up to $2.2 \mu \mathrm{F}$ shown in Fig. 7.

For higher voltage applications, Kemet is giving presentations on DC-Link capacitors for WBG applications showing a COG MLCC $0.22 \mu \mathrm{F} 500 \mathrm{~V} 150{ }^{\circ} \mathrm{C}$ part [9]. The parts have a $\mathrm{Ni}$ /Thin Au termination and can be stacked using a CuSn TLPS process. ESR remains below $3 \mathrm{~m} \Omega$ below $2 \mathrm{MHz}$. Single parts have been demonstrated up to $10 \mathrm{MHz}$. WBG devices allow for higher frequency operation that reduces the need for large capacitors, one possible path to higher density at higher voltages.

Strides are being made in nanoscale materials enabling embeddable tantalum capacitors. Georgia Tech's work on silicon-integrated nanoscale tantalum capacitors is moving toward the goal of passive integration of capacitors and inductors in standard dcdc modules (Fig. 8) [10].

The core of the technology is a Tantalum foil, which enables the construction of a capacitor with the same electrical characteristics of a discrete Multi-Layer Ceramic Capacitor (MLCC) with only $40 \%$ of the thickness. High temperature and high

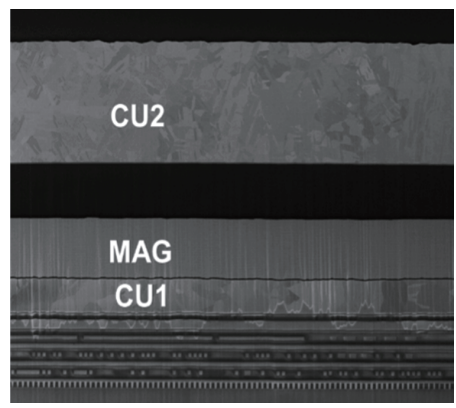

Fig. 9. SEM cross section of magnetic thin-film inductors integrated with CMOS IC.

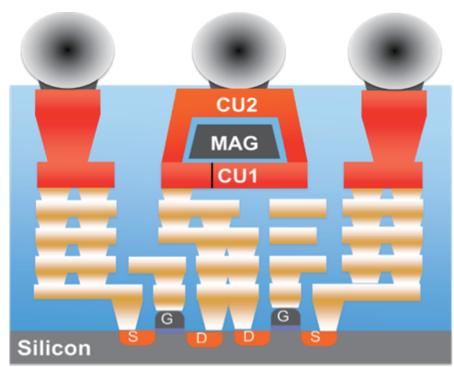

Fig. 10. Illustrated cross section of magnetic thin-film inductors integrated with CMOS IC.

voltage capacitors [10] with hybrid dielectrics composed of nanoscale inorganic and organic dielectrics are also in development targeting a density of $40 \mu \mathrm{F} / \mathrm{cc}$ at $450 \mathrm{~V}$ with operating temperatures up to $175^{\circ} \mathrm{C}$.

\section{3) Magnetics}

The introduction of high-permeability magnetic thin-films to CMOS manufacturing provides a new class of integrated inductor, enabling higher levels of integration and performance for applications that are currently relegated to using discrete inductors. Integrated magnetic thin-film inductors incorporate high permeability $(\mu \mathrm{Rel}>500)$, low coercivity $(\mathrm{HC}<1 \mathrm{Oe})$, magnetic materials to provide a low reluctance path for the coil's magnetic flux, generating a significant inductance enhancement relative to air-core inductors [11]-[13]. These inductors can be fabricated with standard CMOS manufacturing processes and have a low profile $(<30 \mu \mathrm{m})$, which makes them compatible for monolithic integration with CMOS ICs as a back-end process option (Fig. 9, Fig. 10), or for embedding into a variety of packaging substrates on integrated passive devices (IPDs).

These inductors exhibit high inductance for a broad frequency band ( $>1 \mathrm{GHz}$ ), high current density, and low dc resistance relative to existing on-chip inductor technologies. Integrated thin-film magnetic components will enable a new set of IC applications, such as integrated voltage regulation (IVR), where all components of a switched inductor dc-dc power converter are integrated on-chip. Integrated voltage regulation allows power to be delivered to ICs at higher voltages and then be efficiently down converted on-chip, reducing $I^{2} \mathrm{R}$ loss in the upstream power delivery network, and enabling improved power management with a larger number of independently scalable 
on-chip power supplies [14]-[15].

The integration of dc-dc power conversion functions with CMOS provides substantial value in terms of volume, energy efficiency and cost for embedded, mobile and datacenter processors, power-management integrated circuits (PMICs), and other integrated circuit products. Until recently, applications of IVR have been hindered by the unavailability of appropriate integrated power inductors. The emergence of commercially available, thin-film magnetic core power inductors as a backend process option with a wide range of CMOS foundry offerings [16] is a major milestone that allows for application of IVRs to a wide range of computing platforms.

The primary challenges with adopting thin-film magnetic power devices for integrated voltage regulation include IC and system integration challenges in the applications that drive the need IVR. Existing power management architectures for microprocessors have been successively optimized over decades and tailored to individual applications. Commercial adoption of integrated magnetics in IVRs requires integration with these architectures, where board-level power converters shift towards the generation of a smaller number of power supplies with higher output voltage $(1.8 \mathrm{~V}-3.3 \mathrm{~V})$ and improved conversion efficiency to compensate for the introduction of an additional power conversion stage in the IVR. Likewise, microprocessor designers must learn to exploit the new capabilities of IVRs with integrated magnetics to realize all potential energy savings. The staggering complexity of modern computing systems compounds the challenge of introducing these architectural shifts and poses a significant challenge for rapid and large-scale adoption.

\section{4) Manufacturing and Design}

Until recently, the design and manufacture of 3D packaged power sources required a vast array of expertise. Printed circuit boards with embedded components can no longer be assembled in house or at a favorite contractor. A specialized vendor with expertise in imbedding, imbedded component procurement, and final testing is necessary. Expertise in sourcing semiconductor die with proper termination, flatness, and thickness is required. Which capacitor technology are you going use? Should you attempt to form your own in embedded substrate capacitors or buy embeddable capacitors? The same question applies to inductors and resistors. This has been a significant barrier to entry for many power source companies, but help is on the way. The first design and manufacturing partnership was announced in 2016 between UTAC and AT\&S. UTAC is a leading assembly and test services provider and AT\&S is one of the largest producers of embedded substrate power sources. Together, they can take a circuit, then design and manufacture an industry-leading 3D packaged power source using embedded substrate technology.

Many more companies are coming online as suppliers of embedded assemblies with some or all of the capability needed.

\section{B. Additive Manufacturing}

Additive Manufacturing (AM), now synonymous with 3D printing, has escalated in the last few years due to the expiration of several key patents held by companies like 3D Systems and
Stratasys. In recent years, more clarity has been provided as many potential users defined succinct areas for needed development. Recently, the focus is broadening to Direct Digital Manufacturing [17] (DDM), of which 3D printing is a subset. Several topical areas are rapidly evolving: development of greater CAD visualization and definition tools with embedded multiphysics analytics that accelerate the design cycle; language definitions that capture material and object requirements to support integrated 3D additive, subtractive, and finishing manufacturing function; and, in particular, the move to multi-material processing that can provide spatial variation in heterogeneous material characteristics.

The challenge to developing AM for power electronic applications is finding proper materials that have been electrically characterized by the manufacturer, because the vast majority are for mechanical structures. The plethora of materials now being developed is not electrically characterized.

Work is progressing in applying 3D printing to WBG semiconductors and modules. The challenge is in the mechanical interface at the die metallization. Early work back in 1983 showed use of structured copper, which uses fine vertical cooper wires to make direct electrical and thermal contact to the die while providing stress relief. New printing approaches show the use of electron beam melting of $\mathrm{Cu}$ to Direct bonded copper (DBC) as a eutectic attach for Cu-metalized [18].

A substantial advantage would be printing metal on ceramic enabling power packaging which uses thin-printed metal with wire bonding capability [19].

To create integrated power modules that incorporate gate drives, etc.; direct writing of interconnects can be performed using metal loaded polymers (e.g. Ag-Epoxy). Again, this is not supporting thick metal interconnects as might be achieved in the direct writing on direct bond copper (DBC) or semiconductors as noted above. The power packaging laboratory, PREES, at North Carolina State University demonstrated a completed printed power module fashioned after the Vicor module, but with a gate drive integrated into the module lid, which used Ag loaded polymer [20].

More companies are creating machines for printing multilayer circuits. Using post process, electroplating for thicker outer conductors, such machines can quickly prototype gate driver circuits. The Nano Dimension [21], "DragonFly"M 2020 3D Printer deposits two materials, one conductive and one dielectric, in order to build a complete multilayer PCB from the bottom up. Each pass of the print head deposits dielectric and conductive material at the exact location specified by the design file. Starting from the underside conductive traces, the materials are built up to finish with the topside conductors. This process means that vias are built up, drop by drop, either as blind, open, or complete vias. Plated and non-plated through-holes are created by repeatedly leaving a space at a particular XY coordinate, thereby building surrounding materials up around a void. The dielectric ends up as a solid piece within which the conductive traces are positioned at the precise XYZ coordinates specified." This basic approach of Additive Multi-Material is not new science and could be scaled to full roll-to-roll manufacturing. This 
shows great promise for AM at high volume.

The greatest impact to power electronics is the evolving developments in printed magnetics. Though powder-loaded polymers are readily available with fillers, such as graphite and ferrite; the introduction of nano-particles are assisting in densification for increasing desirable magnetic characteristics. Much of the work has been ongoing for military applications, but more industrially driven research is underway. Considerable efforts are now behind the development of fused deposition modelling (FDM)-based printed magnetics.

\section{Nanofluids in Electronic Cooling}

Power requirements for electronic devices have risen steadily in recent years, with the rate of increase sloping upwards, and that has necessitated enhanced thermal management solutions to preserve performance and maintain the mean time between failures (MTBF) of these devices. There are a variety of solutions that can be implemented for cooling high power electronic devices from air to liquid cooling. While air cooling is the default, liquid cooling is necessary when high-power electronic devices dissipate more than $300-520 \mathrm{~W} / \mathrm{cm}^{2}$ [22]-[23]. The addition of nanoparticles to a coolant (i.e. nanofluid) is an alternative that can provide further improvement within a liquid cooled system.

Engineered suspensions of nanoparticles in liquids have become known as nanofluids. The nanoparticles dispersed in a base fluid are typically metal or metal oxide particles with a size range of 1-100 nanometers. When suspended in the base fluid, nanoparticles create a colloidal solution that has been shown to eliminate the issues of erosion, sedimentation, and clogging that plagued earlier solid-liquid mixtures that used larger particles. Dispersion of nanoparticles in a base fluid alters the fluid's overall thermo-physical properties (such as enhancing the thermal conductivity). Researchers were able to demonstrate as much as $20 \%$ enhancement in heat transfer performance of a single-phase, liquid-cooled system when nanoparticles were introduced [24].

The idea of using liquid cooling for power electronics applications is no longer confined to theoretical observations or laboratory experiments. There is widespread use of heat pipes, for example, and personal computers frequently incorporate elaborate liquid cooling systems. Nanofluids represent an enhancement to the technologies that are increasingly being used for cooling electronics.

Much of the ongoing research is focused on immersion cooling and boiling. In tests, boiling with nanofluids has been shown to improve the value of critical heat flux (CHF) by as much as $200 \%$ as a result of nanoparticle deposition on the surface of component. This has led to other research on engineering the surface of high-powered electronic devices with nanoparticles to improve heat dissipation without the need for an engineered liquid.

Researchers are also continually testing new materials to disperse in different fluids: aluminum oxide, iron oxide, zinc oxide, cerium oxide, and bismuth oxide are just some of the options that Nanophase Technologies Corporation offers to customers. In addition, there is work being done with carbon nanotubes that have shown promising results in heat transfer [25]. New materials, such as graphene, are also being developed and tested to determine their potential for application in thermal management.

Other trends in the technology include the use of different materials: Copper, aluminum, and newly developed polymers for the loop of a liquid cooling system or different wicking materials in the production of heat pipes and vapor chambers. In addition, improvements are being made in heat exchangers, pumps, and other components of liquid cooling systems.

While nanofluids have gained momentum in the past two decades, there are still several challenges to their widespread commercialization [26]. One of those challenges is that the concept of nanofluids is still relatively young. The term was only coined in the early 1990s and, while the number of studies has increased in recent years, there are no long-term assessments of how the addition of nanoparticles could affect a cooling system over time. Nanoparticles could collect and cause degradation in a pump or heat exchanger, for example. There is a widespread belief in the stability and reliability of nanofluid solutions, but it has not been possible to document that over a long period of time.

Questions have been raised about the environmental impacts of disposing of nanofluids from a system, whether as vapor, in the case of a nuclear power reactor, or as liquid, when replacing the fluid in a data center system. While it is possible that nanoparticles in high quantities could be harmful, there are few studies that have focused on the environmental impacts [27] or the impact on humans [28].

\section{CONCLUSION}

The discussion herein is just a snapshot in time. PSMA has been publishing these roadmap reports for almost twenty five years, and development activity relating to the next edition is already underway. Technologists who are interested in participating or contributing are encouraged to contact the authors or the PSMA office.

\section{ACKNOWLEDGMENTS}

The named authors of this paper are the report editors. In that role, they were responsible for leading the development of the roadmap and also directly responsible for some of the content. However, much of the report content, and indeed the text in this paper was contributed by a large number of industry experts.

The expert webinars got the roadmap activities underway and thanks are due to those presenters: Siamak Abedinpour, Reza Azizian, Ravi Bhatkal, Mark Cantrell, Jeff Casady, Lorandt Fölkel, Michael Hayes, Alex Huang, Ralph Kerrigan, James Lewis, Pierre Lohrber, Brian Narveson, Brian O’Connell, Stephen Oliver, Ray Ridley, Ajinder Singh, and Hans Stork.

Contributions to the applications trends section were provided by Ajay Hari, Chris Jones, Upal Sengupta, John Vigars, Richard Caubang, Maeve Duffy, Michael Hayes, Anandan Velayutham, Prakash Shahi, Yong Ann Ang, Frazier Pruett, Jim Young and Brian Zahnstecher.

Contributions to the components section came from Vittorio 
Crisafulli, Tim McDonald, Chris Bull, Davide Chiola, Michael Treu, Johannes Schoiswohl, Christophe Basso, Prasad Venkatraman, Tirthajyoti Sarkar, Jeff Casady, Ritu Sodhi and Ali Salih.

Alain Chapuis, Brian Zahnstecher, Ed Massey, Stephen Oliver, John Wiggenhorn, Cahit Gezgin, Jeff Nilles, Arnold Alderman and Ian Mazsa were the contributors for the product trends section.

Contributions to the emerging technologies section also came from Brian Narveson, Ed Herbert, Noah Sturcken, Reza Azizian, Doug Hopkins and Haotao Ke.

Laurie House compiled and prepared the report for publishing and Aung Tu provided critical support and guidance as the past roadmap chair.

And finally thanks to the PSMA Office, the PSMA Board of Directors and all survey participants for their contributions.

We apologize in advance if we inadvertently omitted any other direct contributors.

\section{REFERENCES}

[1] PSMA Power Technology Roadmap Committee (D. B. Dalal and C. A. Quinn, co-chairs), “2017 PSMA power technology roadmap,” ISBN 978-0-9915644-8-4 (Print), 978-0-9915644-9-1 (Digital), March 2017.

[2] PSMA Magnetics Committee, "Power magnetics @ high frequencySolving the black magic", Workshop, Long Beach, CA, USA, March 19, 2016.

[3] PSMA Magnetics Committee, "Power magnetics @ high frequencyEliminating the smoke and mirrors", Workshop, Tampa, FL, USA, March 25, 2017.

[4] PSMA Magnetics Committee, "Power magnetics @ high frequencyEliminating the smoke and mirrors", Workshop, San Antonio, TX, USA, March 3, 2018.

[5] PSMA Capacitor Committee, "Everything you wanted to know about Capacitors but were afraid to ask", Workshop, San Antonio, TX, USA, March 3, 2018.

[6] PSMA Power Technology Roadmap Committee (A. Tu and E. Persson, co-chairs), "2015 PSMA power technology roadmap," ISBN 978-0-9915644-4-6 (Print), 978-0-9915644-7-7 (Digital), March 2015.

[7] S. Garimella, "Transient liquid phase sintering systems for power electronics," Cooling Technologies Research Center (CTRC) Purdue University, 2016 Compendium of Industry-Nominated NSF I/UCRC Technological Breakthroughs.

[8] AVX Corporation, UT Series Ceramic Capacitors.[Online].Available:http://datasheets.avx.com/UT-Series.pdf

[9] J. Bultitude et al., "A comparison between solders \& transient liquid phase sintered interconnects in high temperature multi-layer ceramic capacitors," High Temperature Electronics Network, HiTen 2017 , Cambridge, United Kingdom, July 2017.

[10] P. M. Raj et al., "Emerging high-performance and low-cost power packaging solutions with nanoscale capacitors and inductors," Industry Session, 2017 Applied Power Electronics Conference, Tampa, FL, USA.

[11] N. Sturcken et al., "Magnetic thin-film inductors for monolithic integration with CMOS," 2015 IEEE International Electron Devices Meeting (IEDM), 2015.

[12] C. Mathuna et al., "Review of integrated magnetics for power supply on chip (PwrSoC)," IEEE Transactions on Power Electronics, vol. 27, no.11, pp. 4799-4816, 2012.

[13] D.S. Gardner et al., "Review of on-chip inductor structures with magnetic films," IEEE Transactions on Magnetics, vol. 45, no. 10, pp. 4760-4766, 2009.

[14] E. A. Burton et al., "FIVR: Fully integrated voltage regulators on 4th generation intel core SoCs," Applied Power Electronics Conference and Exposition (APEC), 2014 Twenty-Ninth Annual IEEE, 2014.

[15] N. Sturcken et al., "A 2.5 D integrated voltage regulator using coupled-magnetic-core inductors on silicon interposer," IEEE Journal of Solid-State Circuits, vol. 48, no.1, pp. 244-254, 2013.

[16] N. Sturcken et al., "Magnetic thin-film inductors for monolithic integration with CMOS," 2015 IEEE International Electron Devices Meeting (IEDM), 2015.

[17] D. Chen, S. Heyer, S. Ibbotson, K. Salonitis, J. G. Steingrímsson, and S. Thiede, "Direct digital manufacturing: Definition, evolution, and sustainability implications", Elsevier Journal of Cleaner Production, vol. 107, pp 615-625, ISSN 0959-6526, 16 Nov. 2015.

[18] H. Ke et al, "Investigation of rapid-prototyping methods for 3D printed power electronic module development," IMAPS'14, San Diego, CA.

[19] A. Syde-Khaja and J. Franke, "Selective laser melting for additive manufacturing or high-temperature ceramic circuit carriers," ECTC 2016.

[20] D. Hopkins and H. Ke, "Additive manufacturing in power electronics packagaing,” Industry Session, 2015 Applied Power Electronics Conference, Charlotte, NC, USA

[21] Nanodimension dragonfly product description.[Online].Available: www.nano-di.com.

[22] J. Valenzuela, T. Jasinski, and Z. Sheikh, "Liquid Cooling for High-Power Electronics," Power Electronics Technology 2005.[Online].Available: www.powerelectronics.com.

[23] R. Saidur, K.Y. Leong, and H.A. Mohammad, "A review of applications and challenges of nanofluids," Renewable and Sustainable Energy Review, vol.15, 2011, pp.1646-1668.

[24] K.V. Wong and O.D. Leon, "Applications of nanofluids: Current and future," Advances in Mechanical Engineering, vol.2, 2010, pp. 519659.

[25] S. Halefadl, T. Maré, and P. Estellé, "Efficiency of carbon nanotubes water based nanofluids as coolants," Experimental Thermal and Fluid Science, vol.53, 2014, pp.104-110.

[26] M.M. Kostic, "Critical issues in nanofluids research and application potentials," Nanofluids, 2013, pp.: 1-54.

[27] European Commission, "What are potential harmful effects of nanoparticles," accessed on Nov. 23, 2016.[Online].Available: http:// ec.europa.eu/health/scientific_committees/opinions_layman/en/nanotechnologies/1-2/6-health-effects-nanoparticles.htm.

[28] Scientific Committee on Emerging and Newly Identified Heath Risks "The appropriateness of existing methodologies to assess the potential risks associated with engineered and adventitious products of nanotechnologies," paper presented to European Commission Health \& Consumer Protection Directorate-General, Mar. 10, 2006.

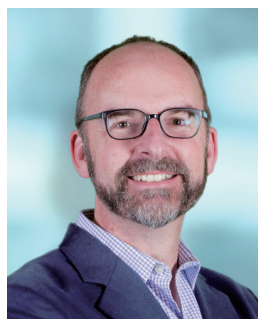

Conor A. Quinn received the B.E. degree in Electrical Engineering from University College Cork, Ireland in 1984, and M.S. and Ph.D. degrees in electrical engineering from the University of Minnesota, U.S.A. in 1990 and 1994 respectively.

His career in the power electronics industry spans 25 years in design, management and technical marketing roles. He has been with Artesyn Embedded Technologies and its predecessor companies since 1997 and currently serves as Senior Director where his responsibilities include strategic technology planning. From 1992 to 1997, he worked at SuperPower, Inc. focusing on supercomputer power systems, uninterruptible power supplies and inverters. He has authored many technical papers in the field of power electronics at IEEE and other industry conferences in the areas of power conversion, power systems and architecture, active filters, photovoltaic inverters and simulation. He has been awarded three patents.

Dr. Quinn has co-authored specifications for the PCI Industrial Computer Manufacturers Group (PICMG) and served on the Boards of Directors of the Smart Management Interface Forum (SMIF) and Power Management Bus (PMBus). He currently serves on the Board of the Power Sources Manufacturers Association (PSMA) and is co-chair of the Power Technology Roadmap committee. He is also co-chair of Industry Sessions for the Applied Power Electronics Conference (APEC). 


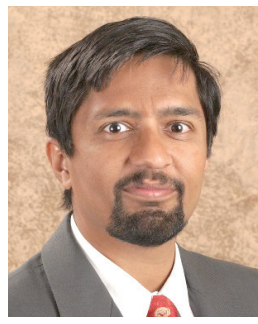

Dhaval B. Dalal received B.Tech. degree in Electrical Engineering from Indian Institute of Technology, Bombay in 1985, and M.S. in Electrical Engineering from Virginia Tech, in 1987. He also has a Master of Science in Management of Technology from Walden University in 1999

He started his professional career working as a Power Electronics Engineer at Digital Equipment Corporation in 1987. From 1992 to 1994, he conducted research in power supply applications at Philips Laboratories. From 1994 to 2002, he worked at Unitrode Corporation/Texas Instruments fulfilling roles in product definition, application, technical marketing, system engineering and product line management. From 2002 to 2008, he worked at ON Semiconductor as Director of Systems Engineering where he was responsible for defining the strategy, roadmaps and technical content of many products for power supply applications. From 2008 to 2014 he was an independent consultant, developing reference designs and solutions for power electronics applications. Since 2014, he has been working as a System Engineering Director at ON Semiconductor, Phoenix, USA with product development and system engineering responsibilities.

He has published and presented more than 25 technical articles, papers and invited talks. He is currently on the Board of Directors of PSMA (Power Sources Manufacturers' Association). He serves as the co-chair of Power Technology Roadmap Committee for PSMA and is also a participant in the iNEMI roadmap activity. Dhaval holds five U.S. patents. 